\title{
Sweetpotato Grown from Root Pieces Displays a Significant Genotype $\times$ Environment Interaction and Yield Instability
}

\author{
Nicholas A. George ${ }^{1}$ \\ Department of Horticultural Science, North Carolina State University, 214 \\ Kilgore Hall, Campus Box 7609, Raleigh, NC 27695; and the Department of \\ Plant Sciences, the University of California, Davis, One Shields Avenue, \\ Davis, CA 95616
}

\author{
Mark Shankle and Jeff Main \\ Pontotoc Ridge-Flatwoods Branch Experiment Station, Department of Plant \\ and Soil Sciences, Mississippi State University, P.O. Box 9555 Mississippi \\ State, MS 39762
}

Kenneth V. Pecota

Department of Horticultural Science, North Carolina State University, 214 Kilgore Hall, Campus Box 7609, Raleigh, NC 27695

\section{Consuelo Arellano}

Department of Statistics, North Carolina State University, 2311 Stinson Drive, Campus Box 8203, Raleigh, NC 27695-8203

\section{G. Craig Yencho \\ Department of Horticultural Science, North Carolina State University, 214 Kilgore Hall, Campus Box 7609, Raleigh, NC 27695}

Additional index words. genotype $\times$ environment, Ipomoea batatas, root piece planting, sweetpotato

\begin{abstract}
Various workers have attempted to develop a root piece planting system for sweetpotato, similar to the system used commercially for potato, but attempts to select and breed sweetpotato clones adapted to root piece planting have met with mixed success. It has been hypothesized this is the result of significant genotype $\times$ environment effects, which are complicating phenotype screening. The aim of this work was to investigate genotype $\times$ environment interactions and yield stability of sweetpotato grown from cut root pieces. Ten sweetpotato clones were grown from cut root pieces in three locations over three seasons at sites in North Carolina and Mississippi. The study found sweetpotato clones grown from root pieces were influenced by both genetic and environmental factors and that the interaction was often complicated and dependent on the trait being measured. A significant genotype $\times$ environment interaction and yield instability were found to be present. Further work will be required to understand the nature of the genotype $x$ environment effects; however, the results suggest programs aiming to develop sweetpotato clones adapted to root piece planting will need to use appropriate multienvironment screening so as to account for genotype $\times$ environment effects.
\end{abstract}

In developed, nations sweetpotato (Ipomoea batatas) is grown predominantly for high-value fresh consumption and processed food markets,

\footnotetext{
Received for publication 10 Mar. 2014. Accepted for publication 30 May 2014.

The project was funded by a grant from the Biofuels Center of North Carolina.

We sincerely thank the staff of the NCSU Sweetpotato Breeding and Genetics Program, the Horticultural Crops Research Station, Williamsdale Farm and Agricultural Extension and Research Center, and the MSU Pontotoc Ridge-Flatwoods Branch Experiment Station for their support of this research. ${ }^{1}$ To whom reprint requests should be addressed; e-mail nicgeorge@ucdavis.edu.
}

but is also increasingly used for producing value-added foods and bio-based industrial products (United States Sweet Potato Council, 2011; Ziska et al., 2009). Sweetpotato is compositionally well suited to these end uses, but crop production is relatively costly, which has restricted an expansion of these alternative markets.

The high cost of sweetpotato production can be attributed in part to the need for manual labor during crop establishment and harvest. Establishment of sweetpotato crops in developed countries involves the production and transplanting of unrooted sprouts, known as "slips." In the United States, slip production and transplanting are together estimated to comprise between $15 \%$ and $20 \%$ of total production costs (Estes et al., 2002; Hinson and Boudreaux, 2007; Martin et al., 2000; Mississippi State University, 2007). Various workers have investigated a planting system for sweetpotato that uses root pieces, similar to the system used for potatoes (Solanum tuberosum) (George et al., 2011). Root piece planting systems can be mechanized more readily than slip planting and therefore have the potential to reduce labor needs, thereby reducing production costs. Despite a long history of research and development, the root piece planting technique is not commonly used in commercial sweetpotato production anywhere in the world.

Existing commercial sweetpotato clones tend to be poorly suited to planting from root pieces, producing lower yields, lower stand establishment, and poorer quality roots than the same clones grown from slips (George et al., 2011). There are examples, however, where different clones, environments, and cultural practices result in yields, stand counts, and root quality comparable to commercial clones grown from slips (George et al., 2011). It has been known for decades that both genetic and environmental factors play a role in the outcome of root piece planting, but the nature and extent of their contribution remain poorly understood (George et al., 2011).

Attempts have been made to select and breed sweetpotato clones that are better adapted to root piece planting, but these attempts have achieved only mixed success with selected clones often having unpredictable and/or unstable yields (George et al., 2011). Sweetpotatoes commonly exhibit a genotype $\times$ environment $(\mathrm{G} \times \mathrm{E})$ interaction (Collins et al., 1987; George et al., 2011; Grüneberg et al., 2005; Kanua and Floyd, 1988; Manrique and Hermann, 2002; Ngeve, 1993). If $G \times E$ effects also influence sweetpotato crops established from root pieces, and breeding programs have not taken this into account, it may explain the mixed success of attempts to develop clones that are better adapted to root piece planting. The objective of this work was to investigate $\mathrm{G} \times \mathrm{E}$ effects in sweetpotato grown from root pieces so as to better understand the phenomenon and provide guidance for future research and development activities relating to root piece planting.

\section{Material and Methods}

Varieties, trial sites, soils, and fertilization. Ten sweetpotato clones, comprised of eight experimental selections and two commercial cultivars, were chosen for the work. The experimental sweetpotato clones were NCDM02-105, NC03-417, NC03-089, NC04-097, NC03-007, NC05-536, NC06312, and NC93-17. These clones had a range of parental backgrounds and had previously been selected by the North Carolina State University Sweetpotato Breeding and Genetics Program (NCSU SBGP) for adaptation to root piece planting. The commonly available commercial lines Beauregard and Covington were also included in the trials. The 
Breeding, Cultivars, Rootstocks, and Germplasm Resources

Table 1. Details regarding the research sites used for this research.

\begin{tabular}{|c|c|c|c|}
\hline Site & Site name & Location & Soil type \\
\hline Clinton & $\begin{array}{l}\text { The Horticultural Crops Research } \\
\text { Station, NC Department of Agriculture } \\
\text { and Consumer Services }\end{array}$ & $\begin{array}{l}\text { Clinton, NC; long. } 35.024^{\circ} \mathrm{N} \text {, } \\
\text { lat. } 78.28^{\circ} \mathrm{W}\end{array}$ & Norfolk and Orangeburg loamy sands \\
\hline Wallace & $\begin{array}{l}\text { Williamsdale Farm and Agricultural } \\
\text { Extension and Research Center, North } \\
\text { Carolina State University }\end{array}$ & $\begin{array}{l}\text { Wallace, } \mathrm{NC} \text {; long. } 34.762^{\circ} \mathrm{N}, \\
\text { lat. } 78.099^{\circ} \mathrm{W}\end{array}$ & $\begin{array}{l}\text { Noboco loamy fine sand and Goldsboro } \\
\text { loamy sand }\end{array}$ \\
\hline Pontotoc & $\begin{array}{l}\text { Pontotoc Ridge-Flatwoods Branch } \\
\text { Experiment Station, Mississippi State } \\
\text { University }\end{array}$ & $\begin{array}{l}\text { Pontotoc, MS; long. } 34.136^{\circ} \mathrm{N} \text {, } \\
\text { lat. } 89.003^{\circ} \mathrm{W}\end{array}$ & Flatwoods silt loam \\
\hline
\end{tabular}

Table 2. Details regarding experimental sites used in this study.

\begin{tabular}{|c|c|c|c|c|c|c|c|c|c|}
\hline Site & & Clinton & & & Wallace & & & Pontotoc & \\
\hline Season & 2009 & 2010 & 2011 & 2009 & 2010 & 2011 & 2009 & 2010 & 2011 \\
\hline Planted & 22 May & 12 May & 4 May & 21 May & 30 May & 2 May & 16 June & 19 May & 23 May \\
\hline Harvested & 16 Oct. & 19 Oct. & 19 Oct. & 26 Oct. & 9 Nov. & 26 Oct. & 11 Oct. & 19 Oct. & 17 Oct. \\
\hline $\operatorname{CEC}\left(\mathrm{meq} / 100 \mathrm{~cm}^{3}\right)$ & 3.5 & 2.7 & 9.1 & 5.6 & 7.2 & 5.3 & NA & NA & NA \\
\hline $\mathrm{pH}$ & 6.25 & 5.9 & 5.75 & 6.1 & 6.6 & 5.3 & 6.4 & 6.6 & 5.6 \\
\hline $\mathrm{N}$ fertilization $\left(\mathrm{kg} \cdot \mathrm{ha}^{-1}\right)$ & 0 & 0 & 0 & 0 & 0 & 0 & 40 & 40 & 60 \\
\hline P fertilization $\left(\mathrm{kg} \cdot \mathrm{ha}^{-1}\right)$ & 45 & 45 & 45 & 0 & 0 & 45 & 60 & 60 & 110 \\
\hline $\mathrm{K}$ fertilization $\left(\mathrm{kg} \cdot \mathrm{ha}^{-1}\right)$ & 110 & 110 & 110 & 0 & 0 & 110 & 340 & 220 & 340 \\
\hline B fertilization $\left(\mathrm{kg} \cdot \mathrm{ha}^{-1}\right)$ & 0.6 & 0.6 & 0.6 & 0 & 0 & 0.6 & NA & NA & NA \\
\hline
\end{tabular}

$\overline{\mathrm{CEC}}=$ cation exchange capacity; $\mathrm{P}=$ phosphorus; $\mathrm{K}=$ potassium; $\mathrm{N}=$ nitrogen; $\mathrm{B}=$ boron; $\mathrm{NA}=$ not available.

Table 3. Climatic conditions during the growing season at the research sites used in this study.

\begin{tabular}{|c|c|c|c|c|c|c|c|c|c|}
\hline \multirow{2}{*}{$\begin{array}{l}\text { Site } \\
\text { Season }\end{array}$} & \multicolumn{3}{|c|}{ Clinton } & \multicolumn{3}{|c|}{ Wallace } & \multicolumn{3}{|c|}{ Pontotoc } \\
\hline & 2009 & 2010 & 2011 & 2009 & 2010 & 2011 & 2009 & 2010 & 2011 \\
\hline Annual maximum temperature $\left({ }^{\circ} \mathrm{C}\right)$ & 36 & 38 & 39 & 37 & 37 & 40 & 36 & 38 & 38 \\
\hline Average daily minimum temperature $\left({ }^{\circ} \mathrm{C}\right)$ & 19 & 19 & 19 & 18 & 17 & 17 & 19 & 19 & 18 \\
\hline Average daily temperature range $\left({ }^{\circ} \mathrm{C}\right)$ & 19 & 19 & 19 & 18 & 18 & 18 & 19 & 19 & 18 \\
\hline Total seasonal precipitation (mm) & 432 & 719 & 562 & 708 & 818 & 741 & 687 & 314 & 425 \\
\hline Maximum daily precipitation (mm) & 43 & 71 & 54 & 130 & 105 & 78 & 111 & 62 & 72 \\
\hline Total daylight hours at harvest & 1991 & 2165 & 2275 & 2099 & 2135 & 2377 & 1661 & 2061 & 1982 \\
\hline
\end{tabular}

NCSU SBGP had previously found these clones to generally perform poorly when planted as root pieces (George Craig Yencho, personal communication).

Three trial sites were selected for the work, two sites in North Carolina and one site in Mississippi (Table 1). The Clinton site is representative of soils commonly used for commercial sweetpotato production in North Carolina. It is one of two sites used for breeding and selection activities by the NCSU SBGP and is therefore one of the environments where the eight experimental lines were originally selected. The Wallace site is located $\approx 30 \mathrm{~km}$ south of Clinton. The soils are representative of heavier loams found in eastern North Carolina. These soils are not commonly used for commercial sweetpotato production but represent a region where sweetpotato production could be expanded if alternative markets grow. The Pontotoc site, located $\approx 980 \mathrm{~km}$ west of the Clinton and Wallace sites, had a mixture of predominantly silt loam soils with finer
Table 4. The tables show the terms accounting for spatial field trends that were incorporated into the model. ${ }^{z}$

\begin{tabular}{|c|c|c|c|c|c|c|}
\hline \multirow[b]{2}{*}{ Site } & 2009 & 2010 & 2011 & 2009 & 2010 & 2011 \\
\hline & \multicolumn{3}{|c|}{ Total marketable yield } & \multicolumn{3}{|c|}{ Mother piece yield } \\
\hline & \multicolumn{6}{|c|}{ Fixed } \\
\hline Clinton & lra, splrw & ra & splrw & lra & lrw & noeff \\
\hline Wallace & noeff & noeff & noeff & noeff & noeff & noeff \\
\hline Pontotoc & \multicolumn{6}{|c|}{ Random } \\
\hline Clinton & noeff & noeff & noeff & noeff & noeff & noeff \\
\hline Wallace & noeff & noeff & noeff & noeff & noeff & noeff \\
\hline Pontotoc & noeff & noeff & noeff & noeff & noeff & noeff \\
\hline
\end{tabular}

\begin{tabular}{|c|c|c|c|c|c|c|}
\hline & & No. $1 \mathrm{y}$ & & & ning in & \\
\hline & & & & & & \\
\hline Clinton & 1ra & noeff & splrw & splrw & noeff & noeff \\
\hline Wallace & noeff & noeff & noeff & lrw, splrw & noeff & noeff \\
\hline Pontotoc & noeff & lra lrw & noeff & noeff & noeff & noeff \\
\hline & & & & & & \\
\hline Clinton & noeff & noeff & noeff & noeff & noeff & noeff \\
\hline Wallace & noeff & noeff & noeff & noeff & noeff & noeff \\
\hline Pontotoc & noeff & noeff & noeff & noeff & noeff & noeff \\
\hline
\end{tabular}

${ }^{2}$ Field effects incorporated into the model: lra = linear range effect; 1rw = linear row effect; splra = spline range effect; splrw $=$ spline row effect; $r a=$ random range effect; $r w=$ random row effect; noeff $=$ no field effect. 

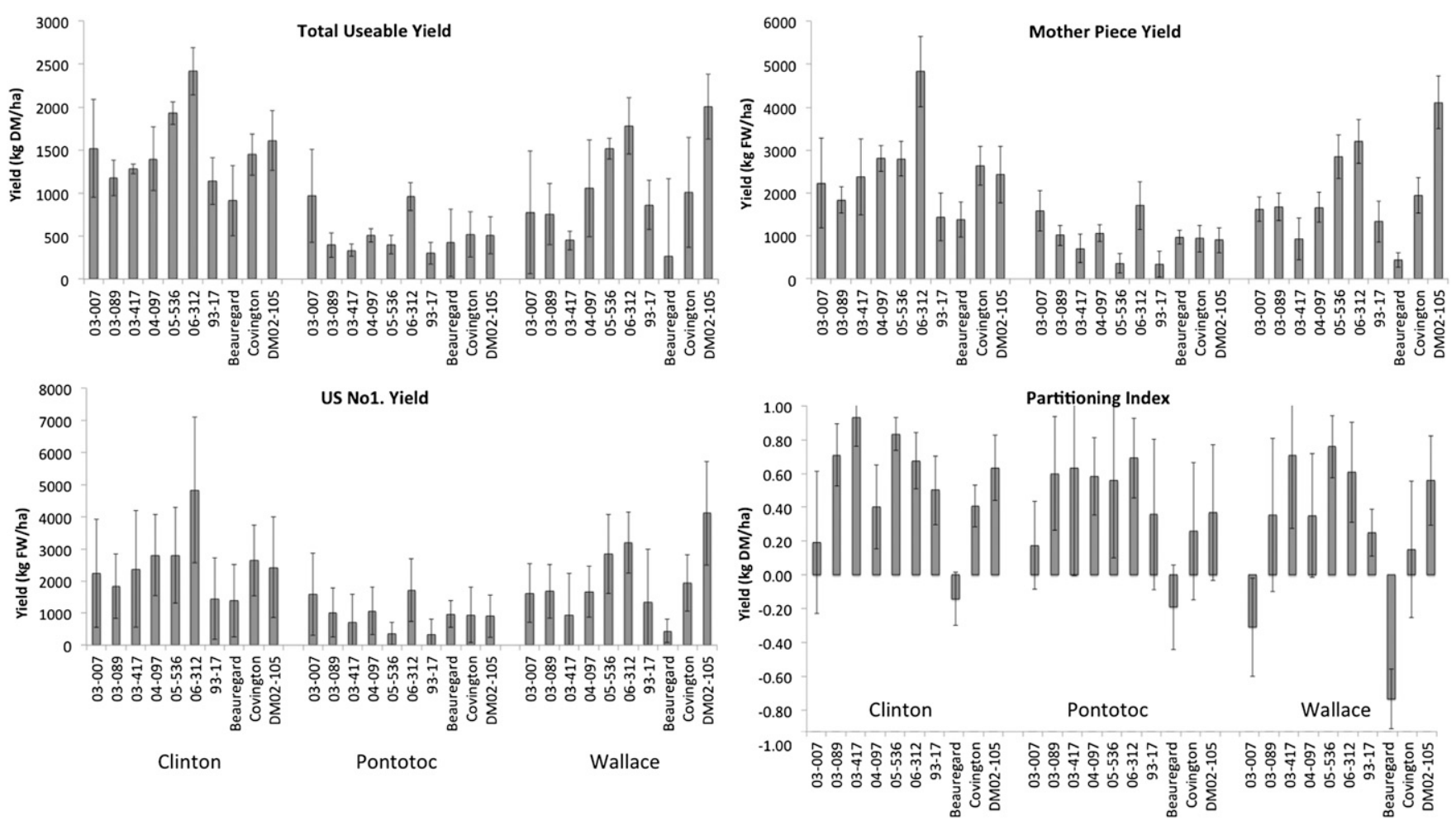

Fig. 1. A summary of the total marketable yield, yield of enlarged root pieces (mother pieces), standard U.S. No. 1 yield, and partitioning index for 10 sweetpotato clones grown from root pieces. Values are means across seasons and replicates. Error bars show SD.

montmorillonite clay subsoils. These soils are commonly used for sweetpotato production in Mississippi. Trials were established at each site in the 2009, 2010, and 2011 seasons, and all clones were grown at every site in every year. The use of 10 clones, three sites, three seasons, and four replications per site had been previously found to provide acceptable error variance in trials of sweetpotato grown from slips (Collins et al., 1987).

Soil analyses for the North Carolina sites were conducted by the Agronomic Division of the North Carolina Department of Agriculture and Consumer Services, and soil analyses for the Mississippi sites were conducted by the Mississippi State University Extension Service Soil Testing Laboratory (Table 2). Additional soil information was obtained from the Web Soil Survey (NRCS, 2013).

Climatic details for each site were obtained from the State Climate Office of North Carolina and the National Climatic Data Center. Daylight hours we obtained from the United States Naval Observatory (USNO, 2012) (Table 3). Growing degree-days were estimated using a basal temperature of $15.6{ }^{\circ} \mathrm{C}$ and maximum temperature of $32{ }^{\circ} \mathrm{C}$ (Villordon et al., 2009).

Propagation material. The Clinton site was used as the source of root material for all the trial sites so as to avoid possible maternal effects on the subsequent performance of sweetpotato crops grown from root pieces. Storage roots weighing between 100 and $200 \mathrm{~g}$ were used. Each root was cut in half transversely to produce a root piece weighing between 50 and $100 \mathrm{~g}$. Root pieces were treated with Dicloran $\left(1 \mathrm{~g} \cdot \mathrm{L}^{-1}\right)$ for control of

Table 5. A summary of the output from the linear mixed models fitted to data from sweetpotato grown from root pieces. ${ }^{\mathrm{z}}$

\begin{tabular}{lrrrlrrr}
\hline Total marketable yield & df & F value & $P$ value & Mother piece & df & F value & $P$ value \\
\hline (Intercept) & 1 & 20.8 & $<0.01$ & (Intercept) & 1 & 62.1 & $<0.01$ \\
Site & 2 & 2.4 & 0.11 & Site & 2 & 16.3 & $<0.01$ \\
Year & 2 & 33.0 & $<0.01$ & Year & 2 & 11.9 & $<0.01$ \\
Clone & 9 & 2.4 & $<0.01$ & Clone & 9 & 6.2 & $<0.01$ \\
Site $\times$ year & 4 & 8.7 & $<0.01$ & Site $\times$ year & 4 & 6.5 & $<0.01$ \\
Site $\times$ clone & 18 & 4.2 & $<0.01$ & Site $\times$ clone & 18 & 3.3 & $<0.01$ \\
Year $\times$ clone & 18 & 4.5 & $<0.01$ & Year $\times$ clone & 18 & 1.4 & 0.14 \\
Site $\times$ year $\times$ clone & 36 & 3.1 & $<0.01$ & Site $\times$ year $\times$ clone & 36 & 2.3 & $<0.01$ \\
& & & & & & & \\
U.S. No. 1 & & & & Partitioning index & & & \\
(Intercept) & 1 & 7.0 & $<0.01$ & (Intercept) & 1 & 0.1 & 0.74 \\
Site & 2 & 1.0 & 0.38 & Site & 2 & 11.3 & $<0.01$ \\
Year & 2 & 12.2 & $<0.01$ & Year & 2 & 48.7 & $<0.01$ \\
Clone & 9 & 2.7 & $<0.01$ & Clone & 9 & 19.8 & $<0.01$ \\
Site $\times$ year & 4 & 4.6 & $<0.01$ & Site $\times$ year & 4 & 11.1 & $<0.01$ \\
Site $\times$ clone & 18 & 2.4 & $<0.01$ & Site $\times$ clone & 18 & 2.6 & $<0.01$ \\
Year $\times$ clone & 18 & 4.6 & $<0.01$ & Year $\times$ clone & 18 & 7.5 & $<0.01$ \\
Site $\times$ year $\times$ clone & 36 & 3.2 & $<0.01$ & Site $\times$ year $\times$ clone & 36 & 2.7 & $<0.01$ \\
\hline
\end{tabular}

Table showing Type 3 test hypotheses of fixed effects.

fungal rots then pre-sprouted at 30 to $32{ }^{\circ} \mathrm{C}$ and $80 \%$ humidity for 1 week in a climate-controlled "pre-sprouting" room.

Field preparation, planting, and harvest. At Clinton and Wallace, Command 3ME (clomazone; FMC Corporation, Philadelphia, PA) at $3 \mathrm{~L} \cdot \mathrm{ha}^{-1}+$ Eptam (EPTC; Gowan Company, Yuma, AZ) at $4 \mathrm{~L} \cdot \mathrm{ha}^{-1}$ pre-plant incorporated were applied for weed control before planting in formed beds, and Lorsban $15 \mathrm{G}$ or $4 \mathrm{E}$ (chlorpyrifos; Dow AgroSciences, Indianapolis, IN) was incorporated 10 to $15 \mathrm{~cm}$ into the soil before planting for insect control. At Pontotoc, the insecticide Capture 2 EC (bifenthrin; FMC Corporation) rather than Eptam was incorporated before bedding at $1.4 \mathrm{~L} \cdot \mathrm{ha}^{-1}$. At Clinton and Pontotoc, Valor (flumioxazin; Valent, Walnut Creek, CA) at $200 \mathrm{~g} \cdot \mathrm{ha}^{-1}$ was applied as a pre-emergent herbicide after bedding. Poast (sethoxydim; BASF Corp., Florham Park, NJ) was applied at the species label rate when grass control was needed. Interrows were cultivated for weed control. Fertilizer application rates are given in Table 2. Fertilizer was applied to meet crop nutrient requirements as determined by soil analyses and field history.

Root pieces were planted either by hand or using a two-row seed-piece planter at a depth of $\approx 5 \mathrm{~cm}$. Pieces were planted on 
an intrarow spacing of $30 \mathrm{~cm}$ with either 20 or 30 pieces per plot with $2.5-\mathrm{m}$ unplanted alleys between plots and 1-m spacing between rows. The sites were arranged in randomized complete block designs with four replicates.

Stand counts were conducted between 30 to $40 \mathrm{~d}$ after planting. Crop growth was allowed to continue for as long as possible before frost risk was considered to be unacceptable. In practice this meant sites were harvested when minimum daily temperatures began dropping below $\approx 10{ }^{\circ} \mathrm{C}$. At harvest, plots were first cut using a flail mower and then roots were unearthed using a chain digger. Roots from each plot were sorted into enlarged root pieces (mother roots) and daughter roots (George et al., 2011). Daughter roots were sorted according to the specifications of the U.S. National Sweetpotato Collaborator Group (the U.S. National Sweetpotato Collaborator Group is a U.S. Department of Agriculture Southern Region Multistate Project, code SERA-005, and is managed by the Southern Association of Agricultural Experiment Station Directors). Approximate size grades of roots were as follows: U.S. No. 1: 5.0 to $9.0 \mathrm{~cm}$ diameter and 7.5 to $23.0 \mathrm{~cm}$ long; canner: 2.5 to $5.0 \mathrm{~cm}$ diameter and 5.0 to $18.0 \mathrm{~cm}$ long; jumbo: larger than U.S. No. 1 in diameter or length or both and without objectionable defects; culls included roots larger than $2.5 \mathrm{~cm}$ in diameter and so misshapen or unattractive that they could not fit as marketable roots in any of the previously described three grades. A sample of three roots was taken from each plot for dry matter determinations. Dry matter data and plot length were used to convert plot yields to dry matter yields per hectare. The yields of U.S. No. 1, jumbo, and canner grade were combined to determine the total usable yield. Partitioning index is a measure of total root yield allocation between daughter roots and enlarged root pieces (mother roots) and is calculated as follows: partitioning index = (daughter root yield - mother piece yield) / (daughter root yield + mother piece yield) (George et al., 2011). A value of greater than zero indicates the majority of the total yield is comprised of daughter roots; a value of less than zero indicates the majority of the total yield is comprised of mother pieces.
Table 6. A summary of the covariance parameters estimates of the mixed models fitted to data from sweetpotato grown from root pieces.

\begin{tabular}{lcr}
\hline & Variance & \multicolumn{1}{c}{ SD } \\
\hline $\begin{array}{l}\text { Total marketable yield } \\
\text { Random effect } \\
\quad \text { (intercept) }\end{array}$ & 2799.3 & 52.9 \\
$\begin{array}{l}\text { Residual } \\
\text { U.S. No. 1 } \\
\text { Random effect } \\
\quad \text { (intercept) }\end{array}$ & 346971.6 & 589.0 \\
$\quad \begin{array}{l}\text { Residual } \\
\text { Root piece } \\
\text { Random effect } \\
\quad \text { (intercept) }\end{array}$ & 32901.8 & 181.4 \\
$\quad \begin{array}{l}\text { Residual } \\
\text { Partitioning index } \\
\text { Random effect } \\
\quad \text { intercept) }\end{array}$ & 127787.4 & 357.5 \\
$\quad$ Residual & 0.00 & 0.04 \\
\hline
\end{tabular}

Data analysis. To determine the significance of the main effects, and their interaction, the data were analyzed as a multienvironment

Table 7. Non-parametric yield stability estimates of sweetpotato grown from root pieces averaged across three seasons.

\begin{tabular}{lcc}
\hline & $\begin{array}{c}\text { Approximate test of } \\
\text { significance for rank }\end{array}$ & $\begin{array}{c}\text { Approximate test of } \\
\text { significance for variance }\end{array}$ \\
\hline Total usable yield & $23.8^{*}$ & $24.9^{*}$ \\
U.S. No. 1 & 16.7 & $18.9^{*}$ \\
Mother piece yield & $27.4^{*}$ & $24.4^{*}$ \\
Partitioning index & 17.2 & $18.6^{*}$ \\
\hline
\end{tabular}

$\chi^{2}=18.3$. Values greater than $\chi^{1}$ indicated instability for either mean rank or variance.

Total useable yield

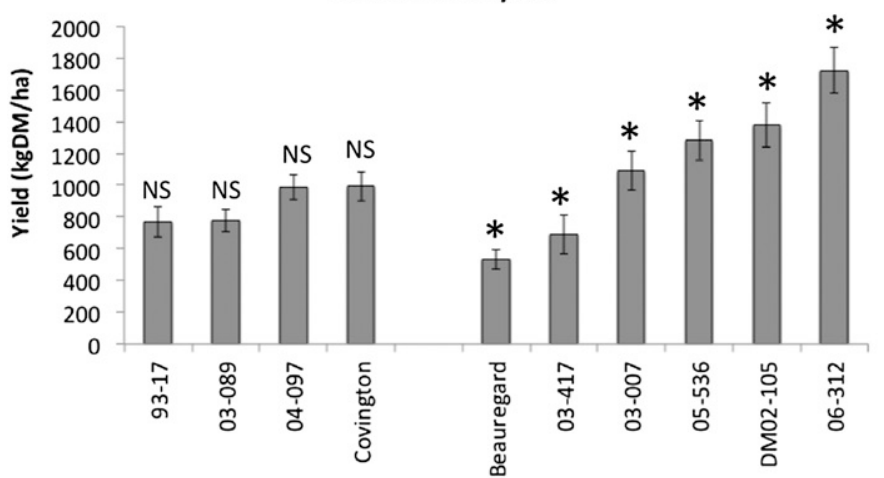

US No. 1

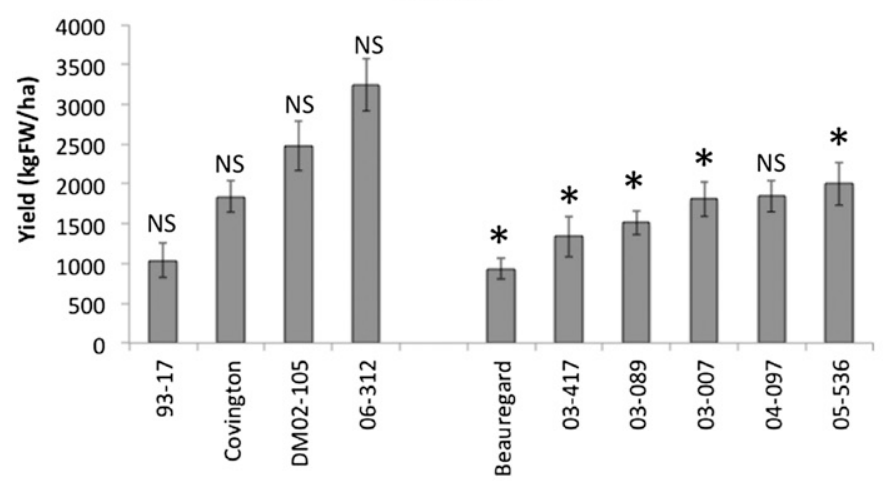

Stable
Unstable

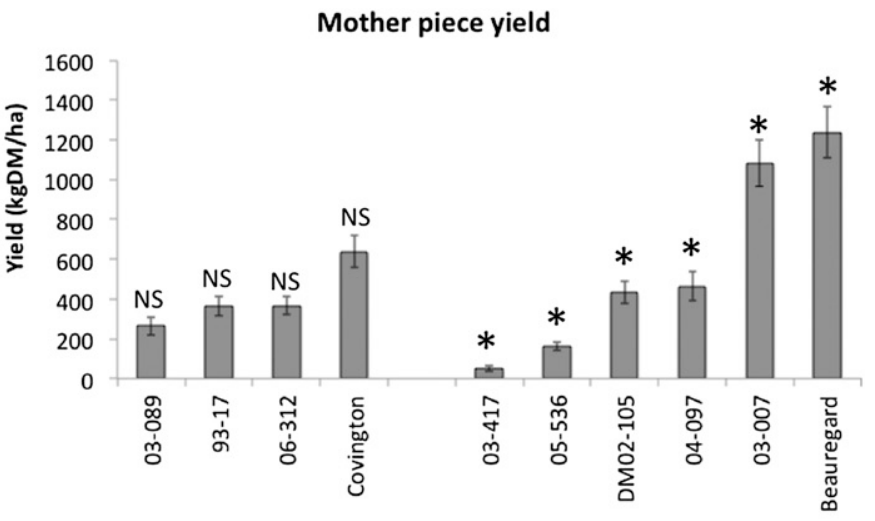

Partitioning index

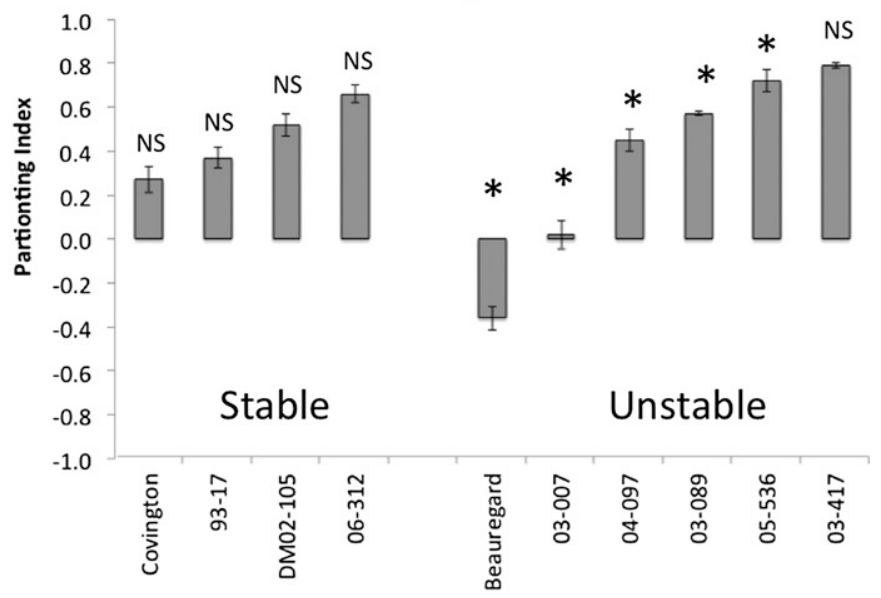

Fig. 2. Non-parametric yield stability estimates of sweetpotato grown from root pieces, averaged across three seasons. *Significant variance instability. NS $=$ nonsignificant variance instability. 


\section{Total marketable yield}

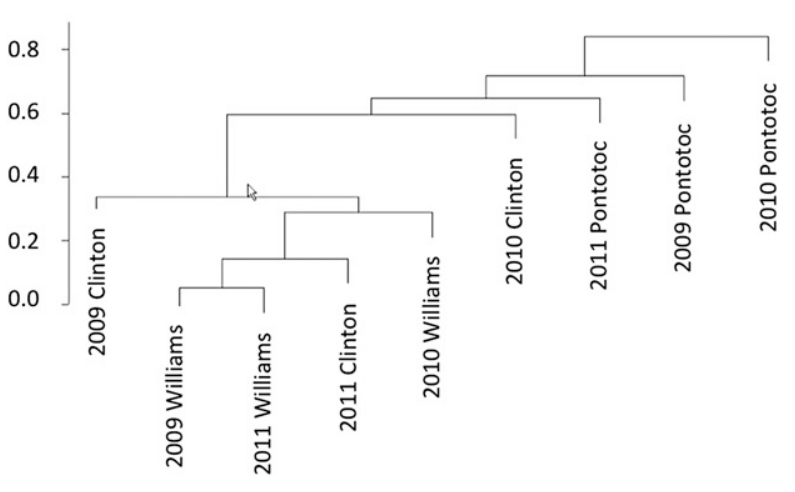

US No1

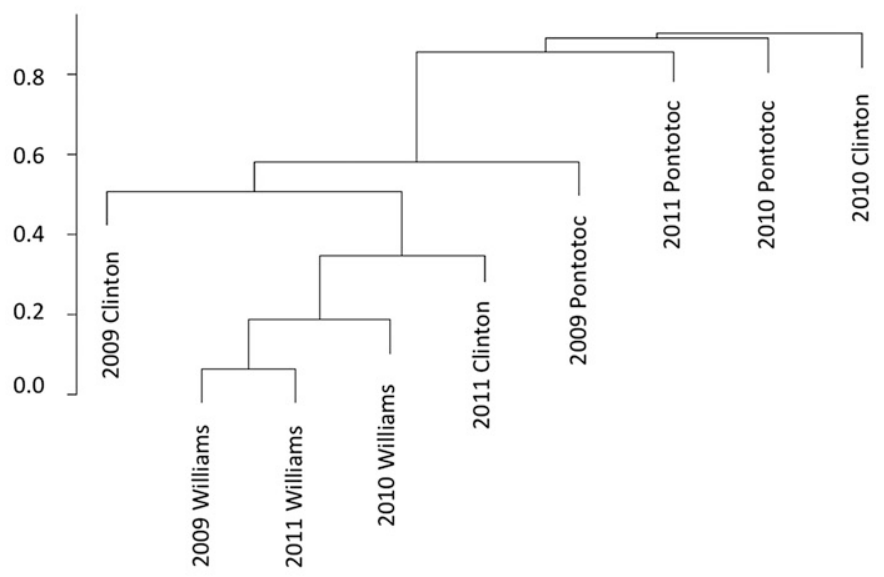

Mother piece yield

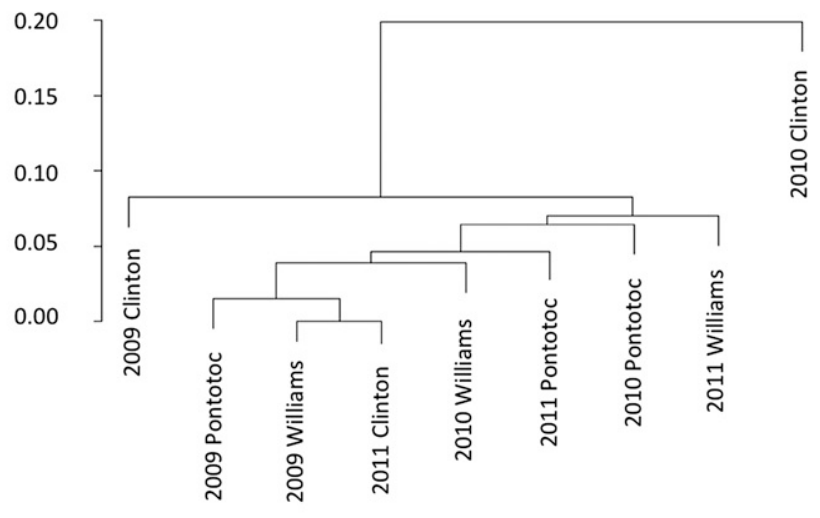

Partitioning index

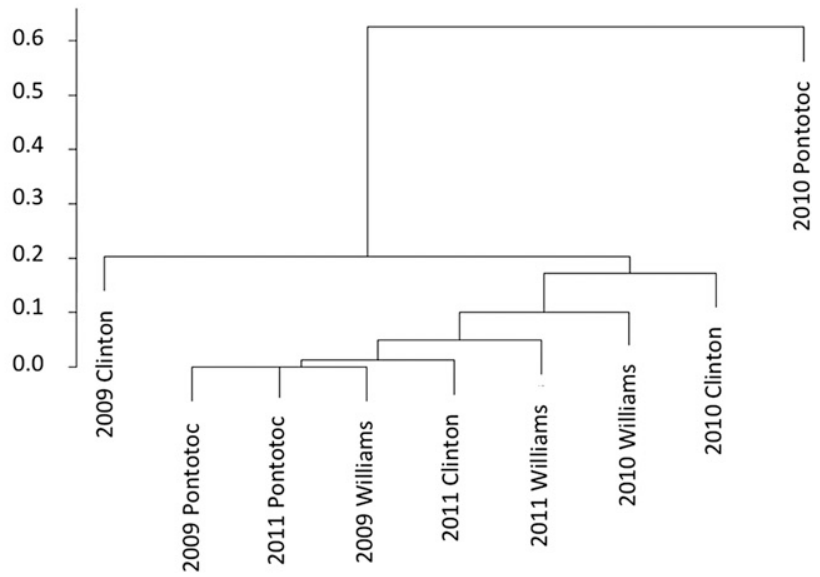

Fig. 3. Dendrograms, produced using an agglomerative (nested) hierarchical clustering, showing the genetic REML estimate of the dissimilarity matrix for additive effects.

trial using a linear mixed model. A linear mixed model was chosen for its ability to use realistic within-trial models for error variation and to combine both random and fixed effects (Smith et al., 2005). Linear mixed models were fit using the CRAN packages lme4 (Pinheiro and Bates, 2000) and nlme (Pinheiro and Bates, 2013) in the R statistical package (R Development Core Team, 2012). The most parsimonious mixed model of the data was selected based on minimization of the Bayesian Information Criterion. Exploratory data analysis investigating different linear mixed models found that the lme function, from the nlme package, produced the most parsimonious mixed model. The lme function is a generic function that fits a linear mixed-effects model but allows for nested random effects, and within-group errors are allowed to be correlated and have unequal variances. The most parsimonious linear model treated site, year, and clone as fixed effects and replicate within both site and year as a random effect. To account for variance heterogeneity in the residuals, separate residual variance was specified for year within site. Normality and variance homogeneity of the linear mixed model were determined by the visual inspections of plots of residuals.

A measure of varietal stability to environmental change is useful for determining if varieties are broadly or specific adapted
(Smith et al., 2005). The add-on package Agricolae CRAN package (Mendiburu, 2010) in the R statistical package was therefore used for nonparametric stability analysis according to Hühn (1990).

To investigate whether significant changes in rank of genotypes were responsible for $\mathrm{G} \times \mathrm{E}$, the data were analyzed as a multienvironment trial (MET) using the program ASReml-R (Gilmour et al., 2005), which implements a factor analytic mixed model analysis adjusted for spatial field trends (Smith et al., 2001a). This type of analysis uses a two-stage approach; first, variety means from individual trials are obtained, then the variety-by-trial mean data are combined with data from all years for an overall mixed model analysis (Smith et al., 2001a, 2001b, 2005). A two-dimensional spatial model (AR1) was used to account for field trends. For more details regarding the ASReml-R program, please refer to Butler et al. (2007). An agglomerative (nested) hierarchical clustering algorithm implemented in the agnes package of $\mathrm{R}$ was used to model the clustering of environments (year by site) (Cullis et al., 2010; R Development Core Team, 2012). The year by location was specified as a fixed effect and variety within site was specified as random. Details regarding field effects incorporated into the model are provided in Table 4.

\section{Results}

Trial outcome and mixed model analysis. For all the measured traits- total marketable yield, yield of U.S. No.1, mother piece yield, and partitioning index-there were differences both among clones within years and between sites (Fig. 1). Visual inspection of the yield data showed Clinton had the highest total marketable yields of dry matter and yields of U.S. No. 1 followed by Wallace. The eight clones previously selected for superior performance when planted as root pieces did not necessarily perform better than the commercial clones Covington and Beauregard. The mean total marketable fresh yield across all years at the Clinton and Pontotoc sites was $3610 \mathrm{~kg} \cdot \mathrm{ha}^{-1}$ for the commercial clones.

The linear mixed model found all main effects, and their interactions, to significantly affect the measured traits (Tables 5 and 6 ) with the exception of site for total marketable yield and U.S. No. 1 and the year $\times$ clone interaction for mother piece yield. Site, year, and the site $\times$ year interaction often explained a greater proportion of the variance than did clone or the interaction of clone with site or 
year, in particular for the yield of mother pieces and partitioning index. Clone and year were found to have a highly significant effect on all the measured traits, and location also significantly affected mother piece yield and partitioning index. The analyses also suggest significant genotype $\times$ location, genotype $\times$ year, and genotype $\times$ location $\times$ year interaction effects were present for all the measured traits with the exception of mother piece yield. The contribution of the effects to total variance differed between the measured traits and the first-order effects were not always higher that the second- or third-order effects (Table 5).

Stability analysis. Significant instability was detected for both the mean and variance of the varieties across all locations and years (Table 7). Mean stability was dependent on the trait being measured. Total marketable yield and mother piece yield were found to be significantly unstable; however, yield of U.S. No. 1 and partitioning index were not. All traits were found to have significant variance instability. Individual clones varied in terms of stability, and mean instability was found to be correlated with variance instability (Fig. 2). Individual clones tended to be either significantly stable or significantly unstable for all four of the measured traits, although not in all cases. For example, Covington was found to be stable for all the measured traits, whereas Beauregard was found to be significantly unstable for all the measured traits. In contrast, 03-089 showed significant instability only for the yield of U.S. No.1 and the partitioning index. The correlation between yield and instability was poor.

Multienvironment trial analysis. The analysis in ASREML-R found the genetic correlation between sites to be complicated (Figs. 3 and 4). The dendrogram produced by agglomerative (nested) hierarchical clustering, showing the genetic REML estimate of the dissimilarity matrix for the total genetic effects, shows that sites did not cluster solely by site, year, or site by year and that the nature and extent of clustering varied depending on the trait being measured (Fig. 3). The Pontotoc site clustered away from the other site by year combinations for total marketable yield and No. 1. The 2010 Clinton site was different for mother piece yield compared with the other sites, which clustered together. The 2010 Pontotoc site diverged substantially from the other sites for the partitioning index. The genetic correlation between sites was dependent on the trait being measured (Fig. 4). Total marketable yield and yield of U.S. No. 1 showed poor genetic correlation between trials, suggesting that significant changes in genotype ranking are occurring for these traits. Genetic correlation was stronger for yield of mother pieces and partitioning index.

\section{Discussion}

This study found that sweetpotato clones grown from root pieces are influenced by both genetic and environmental factors. The total usable yield of dry matter, the fresh

\section{Total marketable yield}

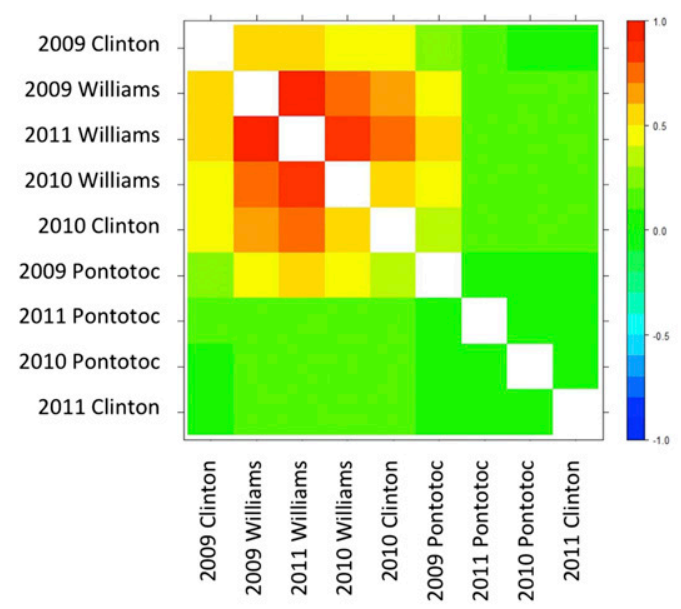

US No1

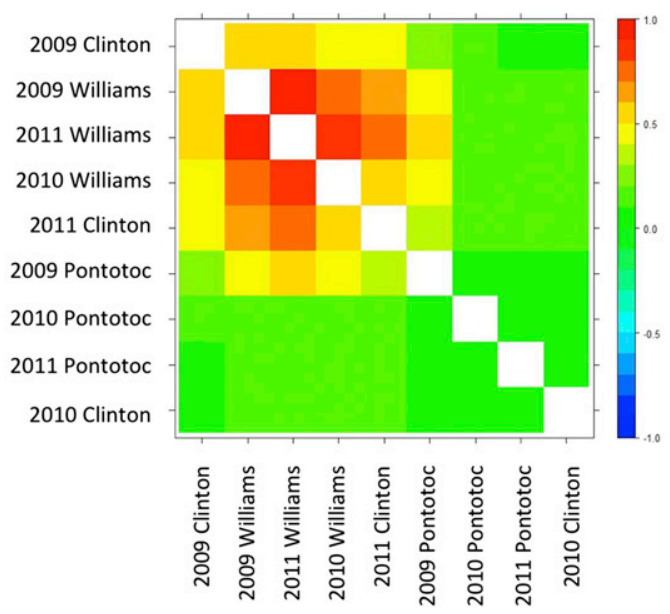

Mother piece yield

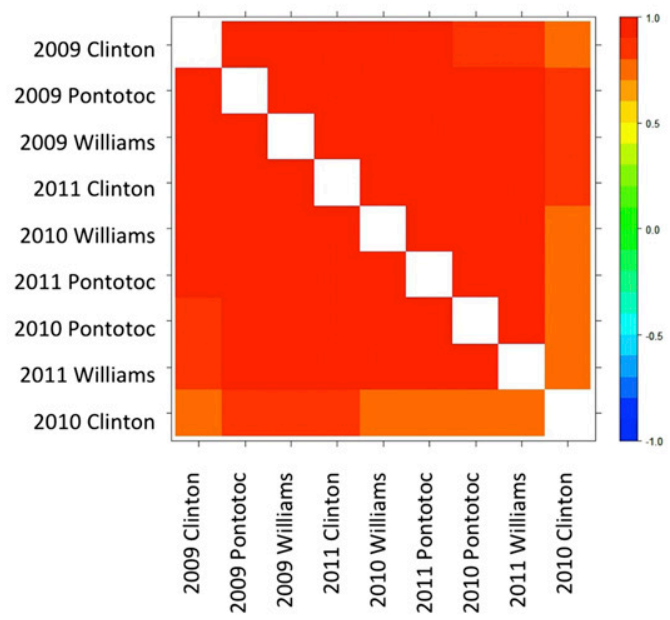

Partitioning index

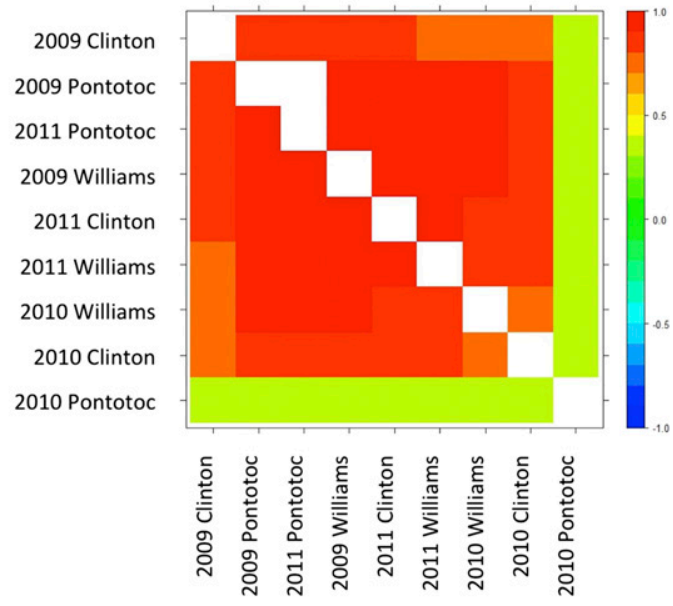

Fig. 4. A heat map of the correlation matrix showing the relationship between the year-by-site interaction for all the measured traits. Key on right hand side depicts the correlation color scale. Environments ordered as per dendrogram in Figure 3. 
yield of U.S. No. 1 roots, the yield of mother pieces, and partitioning index all varied between clone, site, and season (Fig. 1). Significant $\mathrm{G} \times \mathrm{E}$ interactions (Table 4) and yield instability (Table 7; Fig. 2) were detected. The $\mathrm{G} \times \mathrm{E}$ effect was complicated and dependent on the trait being measured. The significant $\mathrm{G} \times \mathrm{E}$ effects were most probably the result of changes in genotype ranking between sites and years, particularly in terms of the total marketable yield and the yield of U.S. No. 1 (Figs. 2, 3, and 4) (Cullis et al., 2010; Hühn, 1990; Smith et al., 2001b). The results of this work therefore support the hypothesis that a significant $\mathrm{G} \times \mathrm{E}$ interaction and yield instability exist in sweetpotato grown from cut root pieces. This has implications for future attempts to develop sweetpotato clones that are better adapted to root piece planting.

It has been found that ascribing particular environmental causes to $\mathrm{G} \times \mathrm{E}$ interaction in sweetpotato grown from slips is challenging (Grüneberg et al., 2005) and therefore determining the cause of the $\mathrm{G} \times \mathrm{E}$ interaction in sweetpotato grown from root pieces was not an aim of this study. However, it was found that year and the year $\times$ site interaction explained the greatest variance in the model for all the measured traits with the exception of yield of mother pieces, which was more heavily influenced by site. This suggests that seasonal effects, and their interaction with site factors, are influencing the yield of daughter roots from sweetpotatoes grown from root pieces. This is in contrast to previous studies that suggest soil type plays a larger and more consistent role in determining the outcome of root piece planting than other environmental factors (George et al., 2011).

The objective of this work was not to make direct a comparison with sweetpotato crops grown from slips; however, the mean marketable fresh yield for slip-grown sweetpotato from North Carolina and Mississippi for this time period was $19.7 \mathrm{Mg} \cdot \mathrm{ha}^{-1}$ (NASS, 2010). This is substantially higher than the 3.6-Mg.ha ${ }^{-1}$ fresh yield of total marketable roots for the root piece-grown commercial clones in this study. This demonstrates that for root piece planting to be a commercially viable alternative to slips, it will be necessary to increase yields.

The results of this study suggest breeding programs aiming to develop sweetpotato clones that produce higher yields when planted as root pieces will need to be cognizant that significant genotype $\times$ location, genotype $\times$ year, and genotype $\times$ location $\times$ year effects will complicate phenotype screening. We therefore recommend that germplasm be screened in multienvironment trials conducted across climatically and edaphically variable sites so that phenotype performance can be properly assessed.
Selection and breeding for both high yields and broad adaptation in sweetpotato are possible; however, yield stability in sweetpotato remains problematic and poorly understood (Grüneberg et al., 2005; Ngeve, 1993). The significant clone $\times$ year $\times$ site effects detected in this work support this. We hypothesize that to better ensure the maintenance of high mean yields across sites and season when using root pieces for propagation, it may therefore be necessary for growers to use multiple sweetpotato clones.

This study was comparatively limited in the number of clones and sites used, so it is possible that the significant $\mathrm{G} \times \mathrm{E}$ effects and rank changes detected were the result of the relatively small number of clones. We therefore recommend a larger number of clones from diverse genetic backgrounds be evaluated. Given the time and economic burden of multienvironment trialing, it would also be valuable to undertake further work to explore causal factors of the $\mathrm{G} \times \mathrm{E}$ interaction observed in this study. This will help to clarify the types of environments that should be used for the screening of germplasm.

\section{Literature Cited}

Butler, D., B.R. Cullis, A.R. Gilmour, and B.J. Gogel. 2007ASReml-R reference manual: ASReml-R estimates variance components under a general linear mixed model by residual maximum likelihood (REML). The State of Queensland, Department of Primary Industries and Fisheries, Brisbane, Queensland, Australia.

Collins, W.W., L.G. Wilson, S. Arrendell, and L.F. Dickey. 1987. Genotype $\times$ environment interactions in sweet-potato yield and quality factors. J. Amer. Soc. Hort. Sci. 112:579583.

Cullis, B.R., A.B. Smith, C.P. Beeck, and W.A. Cowling. 2010. Analysis of yield and oil from a series of canola breeding trials. Part II. Exploring variety by environment interaction using factor analysis. Genome 53:1002.

Estes, E., J. Schultheis, and H. Sampson. 2002. Sweet potato enterprise budget worksheet. NC State University, Raleigh, NC.

George, N.A., K.V. Pecota, B.D. Bowen, J.R. Schultheis, and C.G. Yencho. 2011. Root piece planting in sweetpotato-A synthesis of previous research and directions for the future. HortTechnology 21:703-711.

Gilmour, A.R., B.R. Cullis, B.J. Gogel, S.J. Welham, and R. Thompson. 2005. ASReml user guide. VSN Int., Heml Hempstead, UK.

Grüneberg, W.J., K. Manrique, D. Zhang, and M. Hermann. 2005. Genotype $\times$ environment interactions for a diverse set of sweetpotato clones evaluated across a varying ecogeographic conditions in Peru. Crop Sci. 45:2160-2171.

Hinson, R.A. and J.E. Boudreaux. 2007. Louisiana vegetable crops. Louisiana State University Department of Agricural Economics \& Agribusiness, LA.

Hühn, M. 1990. Nonparametric measures of phenotypic stability. Part 1: Theory. Euphytica 47:189-194.

Kanua, M.B. and C.N. Floyd. 1988. Sweet-potato genotype $\times$ environment interactions in the highlands of Papua-New-Guinea. Tropical Agriculture 65:9-15.

Manrique, K. and M. Hermann. 2002. Effect of GX $E$ interaction on root yield and betacarotene content of selected sweetpotato [Ipomoea batatas (L) Lam.] varieties and breeding clones, p. 281-286. In: Scientist and farmer: Partners in research for the 21st century. Program Report, 1999-2000. International Potato Center, Lima, Peru.

Martin, D.A., R.D. Myers, and C.A. McClurg. 2000. Growing sweet potatoes. Maryland Cooperative Extension, University of Maryland, MD.

Mendiburu, F.d. 2010. Statistical procedures for agricultural research. CRAN.

Mississippi State University. 2007. Traditional and organic vegetables 2008 planning budgets. Mississippi State University, Department of Agricultural Economics, MS.

NASS. 2010. National Agricultural Statistics Service. U.S. Department of Agriculture. <http:// www.nass.usda.gov/>.

Ngeve, J.M. 1993. Regression analysis of genotype $\times$ environment interaction in sweet-potato. Euphytica 71:231-238.

NRCS. 2013. Web soil survey. U.S. Department of Agriculture, Natural Resources Conservation Service. <http://websoilsurvey.nrcs.usda.gov/ app/>

Pinheiro, J.C. and D.M. Bates. 2000. Mixed-effects models in S and S-PLUS. Springer, New York, NY.

Pinheiro, J.C. and D.M. Bates. 2013. Package 'nlme': Linear and nonlinear mixed effect models. R-core.

R Development Core Team. 2012. R: A language and environment for statistical computing. $<$ http://www.R-project.org $>$.

Smith, A., B. Cullis, and A.R. Gilmour. 2001a. The analysis of crop variety evaluation data in Australia. The Australian \& New Zealand Journal of Statistics 43:129-145.

Smith, A., B. Cullis, and R. Thompson. 2001b. Analyzing variety by environment data using multiplicative mixed models and adjustments for spatial field trends. Biometrics 57:11381147.

Smith, A.B., B.R. Cullis, and R. Thompson. 2005 The analysis of crop cultivar breeding and evaluation trials: An overview of current mixed model approaches. J. Agr. Sci. 143: 449-462.

United States Sweet Potato Council. 2011. The United States Sweet Potato Council Inc., Columbia, SC. $<\mathrm{http}: / / \mathrm{www}$.sweetpotatousa.org $>$.

USNO. 2012. Sun or moon rise/set table for one year. U.S. Navy Astronomical Application Department. <http://aa.usno.navy.mil/data/docs/ RS_OneYear.php>.

Villordon, A., C. Clark, D. Ferrin, and D.R. LaBonte. 2009. Using growing degree days, agrometeorological variables, linear regression, and data mining methods to help improve prediction of sweetpotato harvest date in Louisiana. HortTechnology 19: 133-144.

Ziska, L.H., G.B. Runion, M. Tomecek, S.A. Prior, H.A. Torbet, and R. Sicher. 2009. An evaluation of cassava, sweet potato and field corn as potential carbohydrate sources for bioethanol production in Alabama and Maryland. Biomass Bioenergy 33:1503-1508. 